92 and 107 'spheroblasts' should be 'spheroplasts'. On pages 38 and 39 , in Formulae 3 and 4, for isoxazole penicillins $\mathrm{R}$ should be ' $\mathrm{C}_{6} \mathrm{H}_{4} \mathrm{Cl}$ ', not ' $\mathrm{Cl}$ '. In Table 8 on page 100, the formulae of benzyl penicillin, methicillin, oxacillin and penicillin $N$ are wrongly given. 'These and numerous other small misprints should be corrected in any future edition.

The title of the book alone is bound to appeal to many different types of reader, precisely beozuse its subjectmatter covers such a wide range of medical and seientific interests. In this sense the author has attempted to meet a real need, but because of its general and rather superficial nature the book steers a somewhat uncertain course between the extremes of an authoritative treatise on the one hand and a somi-popular essay on the other.

R. KNox

\section{CONTROL OF BACTERIAL DISEASES}

The Battle Against Bacteria

A History of the Development of Antibacterial Drugs, for the General Reader. By P. E. Baldry. Pp. ix $+102+$ 8 plates. (London: Cambridge University Press, 1965.) 22s. 6d. net; 4.50 dollars; Paperback 10s. $6 d$. net.

$\mathrm{T}$ HE belief that diseases were the results of supernatural invocations was prevalent until the first century B.C., when Varro postulated invisible organisms as the causative phenomena. Although knowledge was accumulated on the spread and control of diseases such as leprosy and lague, the identity of these organisms remained a mystery until the development of lens systems in the seventeenth century enabled Van Leeuwenhoek to describe bacteria. Later poor sanitation conditions were recognized as potential sources of cholera, typhoid and dysentery and the significance of 'carriers' also established. However, the battle was only fully engaged during the nineteenth century when methods of growing bacteria in vitro and evaluating some of their characteristic activities were devised. To-day the essential techniques pioneered by men such as Pasteur, Lister and Koch are taken for granted, but the whole of modern microbiology and therapeutics is based on their painstaking investigations and application to the task of allaying disease. Koch's now famous postulates, prompted earlier by his teacher Henle, were timely in dissuading bacteriologists from making unwarranted conclusions and established a strict protocol for the unequivocal identification of pathogens.

The assault on pathogenic bacteria came from two quarters: on the one hand, defensive measures in the form of vaccination, initiated by the work of Jenner on smallpox and enthusiastically developed by Pasteur and others; on the other hand, offensive measures using chemicals to kill bacteria in vivo. Here Ehrlich's concept of antimetabolism provided a basis for the chemotherapeutie attack, and the programme of antimetabolite research pursued by Ehrlich and Domagk led to the fulfilment of their aspirations with the discovery of sulphanilamide. Unfortunately, no mention is made in The Battle Against Bacteria of D. D. Wood's elucidation of the modo of action of this drug and the impact that it had on the later course of medical microbiology. The random approach to chemotherapeutics embodied in the search for antibiotics is treated in the final chapters where discussion is centred on a detailed examination of penicillin and streptomycin.

Dr. Baldry concludes by emphasizing the potentiality of many pathogenic bacteria to acquire drug resistance. The countermeasure of prescribing mixtures of drugs, as in the treatment of tuberculosis, was not, and indeed is not, always appreciated; as a result, gonorrhoea and streptococcal infections, for example, are not always susceptible to penicillin-the one-time panacea for all ills. Finally, our thoughts are focused on the increased longevity of man, due, at least in part, to drug therapy. In somewhat Malthusian terms, the author highlights the question of food supply and population control, and the consequences attenrting an increasing proportion of old people in the community. We are cautioned prudently that "... drugs have produced their own problems which, unless wisely handled, can lead to as much misery as the diseases themselves".

Dr. Baldry has produced a concise, accurate account of the development of therapeutic agents and, throughout, the book creates a sense of excitement in the reader, scientific fact being interspersed with profiles of the major figures, anecdotes and social comment. Aimed at the general reader, The Battle Against Bacteria will be read by non-specialist and specialist alike with much profit and enjoyment.

ALAN T. BULL

\section{THE CELLULAR BASIS OF RADIATION LETHALITY}

Mammalian Radiation Lethality

A Disturbance in Cellular Kinetics. By Victor P. Bond, Theodor M. Fliedner and John O. Archambeau. (American Institute of Biological Sciences and U.S. Atomic Energy Commission. Monograph Series on Radiation Biology.) Pp. xvi+340. (New York: Academic Press, Inc.; London: Academic Press, Ine. (London), Ltd., 1965.) $76 s$.

TO understand the effects of radiation on higher organisms it is necessary to appreciate that the processes of cell division are disrupted by doses which are too small to produce measurable effects on the functions of fully differentiated cells. Thus tissues in which little or no cell division normally occurs may not appear to be affected by radiation, in contrast to those in which the population of functional cells requires continual renewal. In particular, animals will die if either the haemopoietic tissue or the epithelial lining of certain portions of the gastrointestinal tract became too depleted of stem cells and ultimately, therefore, of the functioning cells which arise therefrom.

Mammalian Radiation Lethality reviews most of what is known about the cellular kinetics of these two systems, and deals also with the central nervous system. One of the aims of the authors is to show how the perturbations introduced into the cellular kinetics by irradiation give rise to such radiation syndromes as are observed. Those portions of the book which deal with the kineties of cell renewal are skilfully and adequately handled, and well documented, reflecting the many contributions in this field made by the authors, in particular Dr. V. P. Bond. Their touch is less sure, however, when they deal, in rather meagre fashion, with the fundamentals of cellular radiobiology, and it follows that the message of the book is not as forcibly delivered as it might have been. One chapter only, entitled "Basic Radiobiological Principles Derived from Tissue Culture Systems", is devoted to this major aspect of their main thesis, and an example of its sketchy nature is the omission of any references whatever to fractionation studies. Yet experiments carried out by tissue-culture techniques have demonstrated patterns which have been most impressively repeated in studies on the whole animal, and indeed, the authors have occasion to quote one such experiment, the very point of which was the evidence it provided that it was justifiable to interpret animal deaths in terms of dose effect curves pertaining to cells.

It is perhaps a part of the comparative inadequacy in the cellular radiobiology section that the documentation 